\title{
The Family Environment Assessment: Study of the Use of the EC-HOME in a Brazilian Sample
}

\author{
Natália Martins Dias ${ }^{1}$ \\ Tatiana Pontrelli Mecca \\ Juliana Martins Pontes \\ Josenilda Oliveira dos Santos Bueno \\ Stricto Sensu Graduate Program in Educational Psychology of the Centro \\ Universitário Fieo - UniFIEO, Osasco, SP, Brazil \\ Gabriela Lamarca Luxo Martins \\ Alessandra Gotuzo Seabra \\ Stricto Sensu Graduate Program in Developmental Disorders, Universidade \\ Presbiteriana Mackenzie, São Paulo, SP, Brazil
}

\begin{abstract}
The family environment may impact child development. However, investigating the family environment in Brazil can be a challenge due to the lack of appropriate instruments. To systematize the study of family environment the Home Observation for Measurement of the Environment Inventory (HOME) was developed. The executive functions (EF), important for the control of thinking, behavior and emotion are among the skills affected by variables of the family environment. This study investigated reliability and validity evidences of the Brazilian Early Childhood version of the HOME (EC-HOME). Participants were 63 preschoolers $(M=4.41 \mathrm{y}, S D=0.66)$, and their respective families. Children were evaluated in $\mathrm{EF}$ tasks. Parents responded to an identification and socioeconomic status (SES) questionnaire. Home visits were conducted to apply the EC-HOME, with independent scoring by two evaluators for 20 of them. There was a high interrater agreement and satisfactory Cronbach's alpha coefficient for the total scale. Correlation analysis suggested that the domains of the HOME contain relatively independent contents of the family context. Significant correlations of the HOME domains with SES variables, as well as with children performance in EF tasks, were found. Findings provided some preliminary evidences of validity and reliability of the EC-HOME in a Brazilian sample.
\end{abstract}

Keywords: Child development, psychometrics, executive function.

\section{Avaliação do Ambiente Familiar: Estudo do Uso do EC-HOME em uma Amostra Brasileira}

\section{Resumo}

$\mathrm{O}$ ambiente familiar pode impactar o desenvolvimento infantil. Porém, investigar o ambiente familiar no Brasil pode ser um desafio devido à falta de instrumentos adequados. Para sistematizar o estudo do ambiente familiar foi desenvolvido o Home Observation for Measurement of the Environment Inventory

Mailing address: Secretaria do Programa de Pós-Graduação em Psicologia Educacional, Av. Franz Voegeli, 300, Bloco Prata, andar-1, Osasco, SP, Brazil 06020-190. E-mail: natalia.dias@unifieo.br Acknowledgements: Coordination for the Improvement of Higher Education Personnel (CAPES) Doctoral Schoolarship for G. L. L. Martins, and National Council for Scientific and Technological Development (CNPq) productivity Schoolarship for A. G. Seabra. 
(HOME). Dentre as habilidades afetadas por variáveis do ambiente familiar estão as funções executivas (FE), importantes para o controle do pensamento, comportamento e emoção. Este estudo investigou evidências de validade e fidedignidade da versão Early Childhood (EC-HOME) brasileira do HOME. Participaram 63 pré-escolares $(M=4,41$ anos, $D P=0,66)$, e suas respectivas famílias. As crianças foram avaliadas em tarefas de FE. Os pais responderam um questionário de identificação e de nível socioeconômico (NSE). Visitas domiciliares foram realizadas para aplicar o EC-HOME, com a pontuação independente por dois avaliadores para 20 delas. Observou-se alta concordância entre avaliadores e coeficiente Alpha de Cronbach satisfatório para a escala total. Análise de correlação sugeriu que os domínios do HOME contemplam conteúdos relativamente independentes do contexto familiar. Correlações significativas entre domínios do HOME com variáveis de NSE, assim como com desempenho das crianças nas tarefas de FE, foram encontradas. Achados fornecem algumas evidências preliminares de validade e fidedignidade do EC-HOME em amostra brasileira.

Palavras-chave: Desenvolvimento infantil, psicometria, função executiva.

\section{La Evaluación del Entorno Familiar: Estudio del Uso de lo EC-HOME en una Muestra Brasileña}

\section{Resumen}

El entorno familiar puede afectar el desarrollo infantil. Sin embargo, la investigación del entorno familiar en Brasil puede ser un desafío debido a la falta de instrumentos adecuados. Para sistematizar el estudio del entorno familiar se desarrolló el Home Observation for Measurement of the Environment Inventory (HOME). Entre las habilidades afectadas por variables del entorno familiar son las funciones ejecutivas (FE), importantes para el control del pensamiento, comportamiento y emoción. Este estudio investigó la fiabilidad y validez de la versión Early Childhood (EC-HOME) brasileña del HOME. Participaron 63 niños $(M=4.41$ años, $D E=0.66)$ y sus familias. Los niños fueron evaluados en tareas de FE. Los padres respondieron un cuestionario de identificación y de estatus socioeconómico (ESE). Se hicieron visitas a domicilio para aplicar el EC-HOME, con puntuación independiente por dos evaluadores para 20 de ellos. Hubo alto acuerdo entre evaluadores y el alfa de Cronbach fue satisfactorio para la escala total. El análisis de correlación sugiere que los dominios del HOME comprenden contenido relativamente independiente del contexto familiar. Se encontraron correlaciones significativas entre los dominios del HOME con variables de ESE, así como el rendimiento de los niños en tareas de FE. Resultados proporcionan alguna evidencia preliminar de la validez y fiabilidad del EC-HOME en muestra brasileña.

Palabras clave: Desarrollo infantil, psicometría, función ejecutiva.

Recent studies have shown the impact of socioeconomic variables on neurological and cognitive development in children, making this a matter of importance and growing interest (Noble, Houston, Kan, \& Sowell, 2012; Noble et al., 2015). The structure, materials and interactions that occur in the family context could constitute variables capable of mediating or moderating this relationship. However, in the national context, the verification of hypotheses such as this is compromised by the lack of standardized instruments constructed or adapted for the population for evaluating variables of the family environment.

In Brazil there is only one instrument, the Inventory of Family Resources - RAF (Marturano, 2006), which aims to evaluate the resources of the family environment that can contribute to academic learning in the years of Elementary Education. The RAF, although shown to be a valid and reliable instrument in relation to school performance and adjustment indicators, is not intended to evaluate resources of the family environment in the early stages of development, 
such as the preschool years. Furthermore, due to being an exclusively reported instrument, it does not include direct observation of the environment. Internationally, as well as in the national context, although psychometric data hasn't been published yet and there isn't an available standardized version, one of the most used instruments for evaluating the home environment is the Home Observation for Measurement of the Environment - HOME Inventory.

The HOME inventory was developed by Caldwell and Bradley $(1984,2003)$ in order to systematize the study of the family environment, therefore it was standardized and its validity and reliability evidence verified by the same authors (Caldwell \& Bradley, 2003). The instrument is more than 35 years old and has been studied in several countries (e.g. Bradley, Corwyn, \& Whitesid-Mansell, 1996; Cruz, Abreu-Lima, Barros, Costa, \& Pacheco, 2011; Glad, Jergeby, Gustafsson, \& Sonnander, 2012; Goemans, van Geel, Vedder, \& Bradley, 2014), however, in 2003 all the versions of the instrument were reformulated and standardized, with validity and reliability studies being performed. The instrument is available for clinical use and for research and is currently considered the world reference in the evaluation of the family environment (Caldwell \& Bradley, 2003).

There are nine versions of the inventory, four for typical subjects, which evaluate the home environment from birth to pre-adolescence; two versions for children who are in the care of third-parties, be it relatives or others, such as child minders; and three versions for subjects with atypical development (Caldwell \& Bradley, 2003). This study used the Early Childhood HOME (EC-HOME) version, designed for individuals from 3 to 6 years of age.

In this version it is suggested that the person applying the instrument makes a visit to the residence of the child, where they will respond to 55 items, from direct observation and/or interview with the parent. The items are divided into eight domains: I. Learning Materials; II. Language Stimulation; III. Physical Environment; IV. Responsivity; V. Academic Stimulation; VI. Modeling; VII. Variety; and VIII. Acceptance
(Caldwell \& Bradley, 2003). According to the authors, the application format, i.e., a visit to the residence, provides the opportunity for observation and collection of relevant information regarding physical and material aspects and family interactions that would not be easily detected by other techniques, such as an interview (Caldwell \& Bradley, 2003).

Considering its different versions, the HOME has been used in studies in several countries, however, fewer studies have been conducted specifically seeking to analyze its psychometric properties. Among them, Cruz et al. (2011) evaluated the stability of the quality of the home environment of a group of Portuguese children at three moments: when the children were 1 to 3 years (moment 1), 4 to 6 years (moment 2) and 8 to 10 years of age (moment 3). Another goal of the authors was to analyze the psychometric characteristics of each version of the HOME used, in relation to maternal education and to the developmental (development scale used at moments 1 and 2) and cognitive outcomes of the child (Raven's coloured progressive matrices, used at moment $3)$. Regarding the stability, significant differences were observed in the global scores of the HOME from the first to the second evaluation, however, not throughout the other evaluations. It was found that maternal education and socioeconomic status (SES) presented moderate to high relationships with the HOME score at all three moments of the study. The authors argue that maternal education can influence the family environment in specific ways, such as in the organization of the space, in the material goods available and in the everyday experiences of the child inside and outside the home. With respect to the cognitive and developmental measures, low to moderate relationships were found with the score in the HOME. Specifically considering the EC-HOME version used in the present study, there was no significant relationship with the measure of development used at moment 1 of the study, however, low relationships were observed ( $r=.24$ and .37$)$ with measures of development and intelligence used at moments 2 and 3 , respectively. 
Recently, Goemans et al. (2014) performed the translation and adaptation of the version of the HOME for children from 6 to 10 years of age, and verified its psychometric properties in a sample of 134 Dutch children. The relationships between the domains of the instrument were in part positive and significant, however, of low magnitude, indicating that the HOME evaluates distinct aspects of the family environment. The internal consistency indices of the dimensions and of the total scale were low, ranging from .22 to .67. Conversely, the inter-rater reliability showed better indexes, ranging from .68 to .86. Negative, significant, low magnitude correlations were observed between the scores in the HOME and behavioral problems, particularly externalizing problems and parental stress. Scores in the dimensions and the total score of the HOME also presented significant, positive, low magnitude correlations with the SES. No relationships were observed with the receptive vocabulary of the children.

In Brazil, studies have also been conducted with the instrument. For example, Andrade et al. (2005), in a study carried out in Salvador, used the HOME version for children from 0 to 3 years of age and investigated the relationship between family environment and the cognitive development of the children between 17 and 42 months. Separating the sample according to maternal education (less than 5 years or more than 5 years of schooling), there were significant differences in the score in five of the six domains of the HOME. The education level of the mother was associated with the quality of the environmental stimulation received by the child, with better organization of the physical environment, greater variety in the daily stimulation, with availability of appropriate materials and games for the child, and greater emotional and verbal involvement of the mother with the child. The linear regression model showed that the score in the HOME was able to explain up to $10.6 \%$ of the cognitive performance, as assessed by the Bayley Scale of Infant Development (Bayley, 1993).

Another study by Martins, Costa, Saforcada and Cunha (2004), aimed to investigate the risk factors for low quality family environments.
They used the EC-HOME version with a sample of 630 preschool children, divided into two groups: positive environments (scores $>30$ in the HOME) and negative environments (scores $<30$ in the HOME). Regression analysis showed that reduced family income, a greater number of siblings and many household members, low maternal educational level and the presence of psychiatric disorders in the mother were some of the more associated factors with a low quality family environment. The authors also reported good internal consistency of the instrument for the standardized variables $(\alpha=.99)$. Conversely, the correlations between the domains of the HOME were low, indicating that the instrument presents distinct dimensions in relation to the family environment.

One of the complicating factors for the use of the HOME in national studies is the absence of a standardized Brazilian version of the instrument, with different researchers having access to and using different translations of the inventory. In order to minimize this problem, the present study used the version translated and adapted by Martins (2014). The entire process of translation, back translation and adaptation of the items, as well as the inventory itself, can be found in the original dissertation (Martins, 2014), which also provides preliminary information about the psychometric properties of the instrument. The author evaluated children from 3 to 6 years of age and, considering the full scale and domains of Learning Materials, Language Stimulation, Responsivity and Variety, observed a negative Cronbach's alpha coefficient in relation to the reliability of the HOME. For the other scales, the reliability coefficients were low, generally below .53. The author justified these findings as being mainly due to the inventory not fulfilling the assumption of covariance among the items. Other factors that may help explain the low reliability were the limited sample size and the lack of heterogeneity in the sample, especially in terms of SES, which limited the variability of responses. In this study, some relationships between variables of the HOME and the performance of the children in executive function tests were also presented, providing some evidence 
for the validity of the instrument. For example, there were significant and positive relationships of Learning Materials, Academic Stimulation and Acceptance with the performance of the children in measures of attention, as well as between Modeling and better ability to deal with cognitive conflict. There was also a negative relationship between Responsivity and a measure of attention, suggesting very responsive parents may hinder the development of certain skills, by undermining the autonomy of the child, for example.

Regarding the abilities evaluated in the study described above, specifically the executive functions (EF), some studies have already shown the impact that variables, such as SES or quality of the interaction with parents, have on the development of the child (e.g. Bernier, Carlson, Deschênes, \& Matte-Gagné, 2012; Sarsour et al., 2011). The EF refer to a set of skills responsible for top-down regulation of behavior, cognition and emotions. A widely accepted model suggests that $\mathrm{EF}$ are composed of three basic abilities:

1. Inhibitory control, which includes both the capability to control interference (i.e., the ability to inhibit attention to distractors including selective attention - or inhibit thoughts and memories, and response inhibition, which refers to the ability to inhibit inappropriate behavior;

2. Working memory, the ability to mentally retain and manipulate information; and

3. Cognitive flexibility, the ability to think 'outside the box' and consider different perspectives, as well as changing the attentional focus between tasks (Diamond, 2013). These abilities are developed from childhood, through adolescence, to adulthood, with a pronounced development between 5 and 7 years (Dias \& Seabra, 2013).

Studies have been conducted with the HOME and EF performance tasks. Sarsour et al. (2011) investigated the prediction of single parenthood and family SES for performance in EF tasks and how these associations may be mediated or moderated by the language skills and the family environment, evaluated through the HOME. A total of 60 families of different SES were evaluated, with children who were on average nine years of age. There was a positive, significant relationship of low magnitude between family environment and language skills. The total score in the HOME showed significant positive correlations of low to moderate magnitude with EF, with the highest relationship observed with inhibitory control, as well as partially mediating the relationship between this ability and the SES. The SES was a predictor for abilities of inhibitory control, working memory and cognitive flexibility. However, the family environment factors, such as parental responsivity, enriched activities and the companionship of the family, were the mediators for the association between SES and abilities of inhibitory control and working memory.

Other evidences also indicate that various environmental variables are related to or affect the development of EF, such as disorganized environments, SES, culture, family environment and style of interaction between the child and parents (Bernier et al., 2012; Bibok, Carpendale, \& Müller, 2009; Dawson \& Guare, 2010; Hammond, Müller, Carpendale, Bibok, \& Lebermann-Finestone, 2012). Accordingly, this construct will be used in the investigation of evidence of validity of the EC-HOME for relationships with other variables. The occurrence of relationships with all the scales of the inventory was not expected, nonetheless, it was hypothesized that performances in EF tests would tend to relate to domains that cover variables that are more related to interactions within the family context (e.g. Modeling or Responsivity), rather than those focused on the physical environment itself (e.g. Physical Environment or Learning Materials).

The aim of this study was to investigate some preliminary psychometric features of the $\mathrm{EC}$ version of the HOME inventory in a Brazilian sample. Specifically, the study included: (a) investigation of the reliability of the scale, including inter-rater reliability and internal consistency through Cronbach's Alpha; and (b) investigation of evidence of validity of the HOME through its relationship with other variables, including SES [score in Associação Brasileira 
de Empresas de Pesquisa (ABEP, 2014)] and parental education] and performance of the children in standardized EF tests.

\section{Method}

\section{Participants}

Participants were 63 preschool children, aged 3 to 5 years $(M=4.41$ years, $S D=0.66)$, and their respective family members. Of the 63 children, $33(52.4 \%)$ were girls. Twenty-seven children were Kindergarten I students (mean age $=3.8$ years, $S D=0.42$ ) and 36 Kindergarten II (mean age $=4.9$ years, $S D=0.32$ ). Among the participants, there were no children with intellectual disability (percentile less than 4, as measured by the Columbia Mental Maturity Scale), uncorrected sensory deficits, syndromes or neurological or psychiatric disorders (according to the responses of the caregivers in the Questionnaire for parents). The families were residents of a metropolitan municipality of Greater São Paulo, from a medium-low socioeconomic classification neighborhood. Of the participating family members, $61(96.8 \%)$ responded to the ABEP socioeconomic classification instrument (see instruments), with two families in the socioeconomic category A; 9 in category B1; 18 in category B2; 21 in category $\mathrm{C} 1 ; 7$ in category $\mathrm{C} 2$; and 4 in category D-E. Among the families, the mean years of study of the fathers was 10.7 years $(S D=1.66 ; \min =7, \max =16)$, with this being 10.8 years $(S D=1.74 ; \min =6 ; \max =16$ years) for the mothers.

\section{Instruments}

Home Observation for Measurement of the Environment Inventory - Early Childhood (ECHOME). The EC-HOME (Caldwell \& Bradley, 2003 ) is an instrument for observation and measurement of the family environment. The Early Childhood (EC) version is aimed at children aged between three and six years. The application of the instrument is carried out through a visit that includes observation and the performance of an interview with the people responsible for the child. During the visit, responses are given for the 55 items of the instrument, which are divided into eight subscales: 1 - Learning Materials; 2 - Language Stimulation; 3 - Physical Environment; 4 - Responsivity; 5 - Academic Stimulation; 6 - Modeling; 7 - Variety; and 8 - Acceptance. Of the 55 items, 21 are based on observation of the family environment, 10 on observation or interview and 24 on an interview, preferably with the mother. Each item in each domain is scored dichotomously ( 0 or 1$)$, with the maximum score in the instrument being 55 points (higher scores reflect better evaluation in each domain).

The visit allows the researcher to observe the environment, as well as the behavior of the child and interactions among present family members, providing data that would be difficult to obtain in an interview format. The visit should be scheduled for a time in which the child is awake and involved in their daily routine. It is assumed that the visit does not distort the interaction between the child and parent, because, even though at the start of the visit a change in behavior occurs, throughout the course of the visit the children and parents tend to express their normal reactions. The EC-HOME version used in this study was translated and adapted to Brazilian Portuguese by Martins (2014). In the study, the instrument showed significant correlations with measures of performance in executive functions in preschool children, deriving some evidences of validity for the Brazilian version of the EC-HOME.

Identification Questionnaire for Parents and SES (Qp-ABEP). The parents answered a socioeconomic classification instrument (the Criterion of socioeconomic classification of the Brazilian Association of Research Companies [ABEP, from the name in Portuguese]; ABEP, 2014) and a questionnaire covering important aspects of the child, their health and development, as well as data on the education of the parents $(\mathrm{Qp})$. The estimated time to complete the instruments was 5 to 10 minutes.

Stroop Semantic Test (SST). The SST evaluates the ability of inhibitory control. The test is computerized and divided into two parts. In both, the following figures are presented: "day", "night", "boy" and "girl". In the first part, the 
child must name the images and in the second say the opposite noun of the pair (Example: say "boy" for the image of a "girl"). Each part has 16 items, which are presented for a time of 300 $\mathrm{ms}$. Correct responses and reaction times (RT) are recorded. The application is individual, with an average duration of 10 minutes. The score and RT in Part 2 of the SET and the score and interference RT (performance in part 2 less performance in part 1 of the test) were used. Evidence of its validity for preschool children was published by Trevisan (2010).

Trail Making Test for Preschool Children (TMT-PC). The TMT-PC (Trevisan \& Seabra, 2012) evaluates the ability of cognitive flexibility. It is divided into two parts. In part A, the child is given a sheet with five figures of puppies, which have to be connected in order of size. This part investigates attention, visual search and speed. In part B, figures of bones of sizes respective to the dogs are introduced, and the child must match the dogs with their appropriate bones, in order of size, connecting them alternately. This part of the test, in addition to attention, visual search and speed, also requires cognitive flexibility. The number of correct sequences and the time of execution in each part of the test were used as performance measures. The application is individual, with an average duration of 7 minutes. Evidence of validity and normative data for preschool children were published by Trevisan, Hipólito, Parise, Reppold, and Seabra (2012) and Trevisan and Prust (2012).

Digit Span Task (DT). The DT is based on the proposal of Natale, Teodoro, Barreto and Haase (2008) and evaluates short-term auditory memory (in the forward order) and phonological working memory (in the backward order). In the Forward Order (FO), the individual must repeat a sequence of digits (numbers) presented verbally by the evaluator. In the Backward Order (RO), the individual must repeat the sequence backwards. In both parts, the sequences of digits increase in complexity, ranging from 2 to 9 items. The test is interrupted when the participant makes two consecutive errors. The application lasts approximately 5 minutes. Previous studies have used digit span tasks with preschool children and reported the evidence of validity for the instrument (Natale et al., 2008).

Corsi Block-Tapping Test (CBT). Evaluates short-term visual memory (in the forward order) and visuospatial working memory (in the reverse order). For the application, a wooden base is used with nine blocks of the same color and size. The task is carried out in two phases, forward and reverse order. In the first phase, the examiner touches a predetermined sequence of blocks at a uniform rate (one block per second) so that the participant observes and then reproduces the same sequence. In the second phase, the examiner again touches a predetermined sequence of blocks and the participant must reproduce the sequence in reverse order. In both phases, as the individual responds correctly, the number of items to be memorized increases, from 2 to 10 per sequence. The test is interrupted when the participant makes two consecutive errors. The application lasts approximately 10 minutes. The instrument has been used for school age and preschool children, with evidence of validity and performance expected by age group (Lezak, 1995; Santos, 2005).

Columbia Mental Maturity Scale (CMMS). The CMMS is a standardized test that evaluates the general non-verbal reasoning ability of children between 3 years 6 months and 9 years 11 months of age (Alves \& Duarte 2001). The child is presented with boards with 3 to 5 pictures and is asked to select the picture that is different or does not relate to the others. To do this, the child needs to discover the underlying rule for the organization of the pictures. The test was used to identify children with intellectual disability indicators. The application time is 15 to 20 minutes.

\section{Procedure}

The project was approved by the research ethics committee of the participating university. After the signing of the terms of consent by the parents of the children, the application of the instruments started. At the same time that the consent form was signed, the parents were requested to complete the Qp-ABEP. The children were 
evaluated individually, during the regular school period, in a room provided by the school. The SST, TMT-PC and CMMS instruments were applied in one session each; while the DT and CBT were applied together in the same session, totaling four sessions of approximately 20 minutes for each child.

For the application of the EC-HOME, the families were contacted by telephone and home visits were scheduled. In all cases, on the day of the visit, the child and parent were present, so it was not necessary to reschedule any visit. Each visit lasted approximately 1 hour. The registration protocol of the HOME was completed by the researcher during the course of the visit. The visits were carried out by two researchers, both Master's students of a graduate program in Psychology, who received training for the application of the instrument. In 20 cases $(31.7 \%)$, the visit was carried out by both researchers with the protocols answered independently by both researchers in order to verify the inter-rater reliability of the HOME.

\section{Data Analysis}

Initially, descriptive statistics of the scores in the HOME and EF tests were conducted. For the performance of the subsequent analysis, the adequacy of the data (performance in EF tests, scores in the HOME) regarding the assumption of normality was verified. As the data did not follow the normal curve for the majority of the measures, according to the KolmogorovSmirnov analysis, the use of non-parametric statistics was chosen. Accordingly, in order to control the effect of age on the variables of performance, the Age Deviation Score standard measure of the CMMS was adopted and the performances in $\mathrm{EF}$ tests were converted to $\mathrm{Z}$ scores for each age group. To investigate the inter-rater reliability of the HOME, Intra-Class correlation (ICC) analysis was conducted between the responses of evaluators 1 and 2, considering the domains and the total score. To check the internal consistency, Cronbach's alpha was calculated for the total scale and domains. Spearman's correlation analysis was performed between scores in the HOME domains. To check evi- dence of validity for the relationship with other variables, Spearman's correlation analysis was conducted between the scores in the HOME (domains and total) and: (a) SES variables, specifically ABEP score and parental education; and (b) performance of the children in the EF tests. In the correlation matrices, significant values are highlighted in bold and marginally significant values in bold-italics.

\section{Results}

Table 1 presents the descriptive statistics of the scores in the HOME and EF tests. Analysis of inter-rater reliability revealed high reliability of the measure, considering the total score, with high ICC $(.94 ; p<.001)$ between the independently completed protocols of the HOME. Considering the domains, this coefficient ranged from .82 , considered satisfactory, to .98 . That data is summarized in Table 2. It should be noted that, in the case of the Acceptance domain, it was not possible to calculate the ICC because of the lack of variability in the items of the scale in the protocol of one of the evaluators.

Analysis of internal consistency through Cronbach's Alpha revealed a satisfactory coefficient for the total scale, with Alpha $=.84(55$ items). In addition to the total scale, only the Physical Environment domain presented good internal consistency, with Alpha $=.81$ ( 7 items). The other domains presented unsatisfactory coefficients, all less than .66. This may be linked to the limited number of items in some scales, for example, Acceptance has 4 items. On the other hand, the specific content of some items are more likely to be reflected, as it will be discussed in its turn. As a complement to the analysis of internal consistency, analysis of correlation between the domains were conducted, as shown in Table 3. The total score in the HOME was related to all domains, with magnitudes between low and high, with the exception of Acceptance. The relationships observed between the domains were all positive and mostly between low and moderate. This pattern of relationships suggests that the domains contemplate relatively distinct or independent content within the family context. 
Table 1

Descriptive Statistics of the Scores in the HOME (domains and total) and in the EF Tests

\begin{tabular}{lcclcc}
\hline \multirow{2}{*}{ HOME } & \multicolumn{5}{c}{ EF Tests } \\
\cline { 2 - 6 } & \multicolumn{1}{c}{ M } & $S D$ & & $M$ & $S D$ \\
\hline Learning Materials & 6.59 & 2.09 & Stroop - score Part 2 & 13.42 & 3.67 \\
Language Stimulations & 6.38 & 0.81 & Stroop - RT - Part 2 & 1.35 & 0.44 \\
Physical Environment & 5.52 & 1.93 & Stroop - interference score & -1.77 & 2.99 \\
Responsivity & 5.38 & 1.52 & Stroop - interference RT & 0.63 & 0.32 \\
Academic Stimulation & 4.70 & 0.71 & Digits - FO & 6.30 & 2.60 \\
Modeling & 3.21 & 0.70 & Digits - BO & 1.73 & 1.30 \\
Variety & 6.11 & 1.49 & Corsi - FO & 3.87 & 1.67 \\
Acceptance & 3.97 & 0.18 & Corsi - RO & 1.78 & 1.02 \\
Home- Total & 41.86 & 6.17 & Trails A - sequence & 3.38 & 1.94 \\
& & & Trails A - time & 29.48 & 14.98 \\
& & & Trails B - sequence & 2.82 & 1.89 \\
& & & Trails B - time & 61.11 & 23.18 \\
\hline
\end{tabular}

Note. RT - Reaction time / FO - Forward Order / $\mathrm{BO}$ - Backward Order.

Table 2

Inter-Rater Reliability: Intra-Class Correlation between Protocols of the Independent Evaluators

\begin{tabular}{lc}
\multicolumn{1}{c}{ Scale } & ICC * \\
\hline Learning Materials & .98 \\
Language Stimulation & .82 \\
Physical Environment & .94 \\
Responsivity & .95 \\
Academic Stimulation & .96 \\
Modeling & .92 \\
Variety & .97 \\
Acceptance & $* *$ \\
Home-Total & .94 \\
\hline
\end{tabular}

Notes. * For all correlation, $p<.001 ; * *$ Not calculated. Variable is constant. 
Table 3

Matrix of Correlations between the Domains of the HOME and between Domains and Total Score

\begin{tabular}{|c|c|c|c|c|c|c|}
\hline 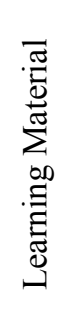 & 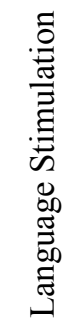 & 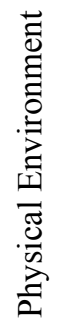 & 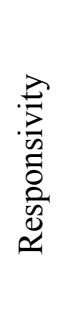 & 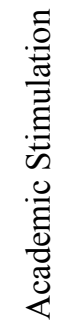 & $\begin{array}{l}\stackrel{\infty}{\Xi} \\
\stackrel{0}{0} \\
\stackrel{0}{\Sigma}\end{array}$ & 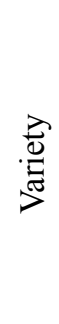 \\
\hline
\end{tabular}

\begin{tabular}{|c|c|c|c|c|c|c|c|c|c|}
\hline \multirow{2}{*}{$\begin{array}{l}\text { Language } \\
\text { Stimulation }\end{array}$} & rho & .46 & & & & & & & \\
\hline & $p$ & .001 & & & & & & & \\
\hline \multirow{2}{*}{$\begin{array}{l}\text { Physical } \\
\text { Environment }\end{array}$} & rho & .45 & .39 & & & & & & \\
\hline & $p$ & .001 & .002 & & & & & & \\
\hline \multirow{2}{*}{ Responsivity } & rho & .63 & .39 & .20 & & & & & \\
\hline & $p$ & .001 & .002 & .123 & & & & & \\
\hline \multirow{2}{*}{$\begin{array}{l}\text { Academic } \\
\text { Stimulation }\end{array}$} & rho & .32 & .16 & .14 & .31 & & & & \\
\hline & $p$ & .010 & .205 & .293 & .015 & & & & \\
\hline \multirow{2}{*}{ Modeling } & rho & -.05 & .19 & -.02 & .18 & .10 & & & \\
\hline & $p$ & .711 & .145 & .863 & . 166 & .449 & & & \\
\hline \multirow{2}{*}{ Variety } & rho & .41 & .32 & .42 & .30 & .36 & .18 & & \\
\hline & $p$ & .001 & .010 & .001 & .015 & .004 & .157. & & \\
\hline \multirow{2}{*}{ Acceptance } & rho & .09 & -.01 & -.02 & .03 & -.09 & -.22 & .09 & \\
\hline & $p$ & .491 & .965 & .902 & .842 & .474 & .087 & .488 & \\
\hline \multirow{2}{*}{ HOME Total } & rho & .80 & .60 & .62 & .70 & .50 & .25 & .70 & .03 \\
\hline & $p$ & .001 & .001 & .001 & .001 & .001 & .045 & .001 & .801 \\
\hline
\end{tabular}

Note. Bold: significant values; Bold-italics: marginally significant values.

Significant positive relationships were identified between the scores in domains of the HOME and the variables of SES, summarized in Table 4. Finally, significant relationships were also found between the performances in the EF tests and some domains of the HOME, these being positive for Modeling, Academic Stimulation and Variety and negative for Language Stimulation. Table 5 presents the relationships found.

\section{Discussion}

This study aimed to investigate some preliminary psychometric features of the EC-HOME, an instrument that systematically evaluates as- pects of the family environment of children between 3 and 6 years of age (Caldwell \& Bradley, 2003). For this, the version translated and adapted to Brazilian Portuguese (Martins, 2014) was used, as the national literature shows a shortage of instruments for this purpose.

Initially, the reliability of the instrument was verified, considering as sources of errors: the subjectivity of the evaluators and the consistency of the items. Significant ICC indices of high magnitude were observed between the scores of the evaluators, both for the total score, and for the domains. Such correlations indicate good reliability and little divergence between the scores assigned by the evaluators (Urbina, 2007). These results are similar to findings of 
Table 4

Matrix of Correlations between the Domains of the HOME and NSE Variables

\begin{tabular}{|c|c|c|c|c|}
\hline & & SES (ABEP) & Education Mother & Education Father \\
\hline \multirow{2}{*}{ Learning Material } & Rho & .06 & .23 & .25 \\
\hline & $P$ & .628 & .085 & .066 \\
\hline \multirow{2}{*}{ Language Stimulation } & Rho & .20 & .21 & .20 \\
\hline & $P$ & .130 & .116 & .134 \\
\hline \multirow{2}{*}{ Physical Environment } & Rho & .43 & .29 & .25 \\
\hline & $P$ & .001 & .027 & .058 \\
\hline \multirow{2}{*}{ Responsivity } & Rho & .05 & .19 & .13 \\
\hline & $P$ & .687 & .147 & .340 \\
\hline \multirow{2}{*}{ Academic Stimulation } & Rho & .02 & -.20 & .01 \\
\hline & $P$ & .885 & .130 & .971 \\
\hline \multirow{2}{*}{ Modeling } & Rho & .20 & .16 & .07 \\
\hline & $P$ & .130 & .234 & .613 \\
\hline \multirow{2}{*}{ Variety } & Rho & .16 & .39 & .41 \\
\hline & $P$ & .216 & .002 & .002 \\
\hline \multirow{2}{*}{ Acceptance } & Rho & .17 & -.05 & .37 \\
\hline & $P$ & .197 & .704 & .005 \\
\hline \multirow{2}{*}{ HOME Total } & Rho & .21 & .28 & .28 \\
\hline & $P$ & .102 & .029 & .039 \\
\hline
\end{tabular}

Note. Bold: significant values; Bold-italics: marginally significant values.

Goemans et al. (2014), although these authors used the version for children from 6 to 10 years of age, the domains of which are partially similar to the EC-HOME. An exception was observed in the Acceptance domain, in which the calculation of concordance between the evaluators was not carried out because there was no variability in the scores in this domain assigned by one of the evaluators. This can be explained by the content evaluated in the domain, i.e., the items evaluate the occurrence of punishment, such as 'shouting at', physically restraining or 'hitting' the child, with three of the four items being scored by observation. Thus, it can be inferred that such occurrences rarely happened during the visits. Future studies could investigate the most effective ways to measure this dimension.

Regarding the internal consistency, the alpha coefficient of the total score in the EC-
HOME and the Physical Environment domain proved adequate according to the testing standards (Urbina, 2007). Although adequate, the alpha coefficient for the total score obtained in this study was lower than that observed by Martins et al. (2004). In other domains the indices were less than .66. Although unsatisfactory, these results corroborate previous findings in the literature, which indicate poor internal consistency for the EC-HOME (Martins, 2014) and for the other versions of the instrument (Goemans et al., 2014). Furthermore, in general, there were correlations of low to moderate magnitude (according to Dancey \& Reidy, 2006) between the domains. These findings corroborate previous studies, such as Martins et al. (2004), in which low correlations were observed between the domains of the HOME, suggesting that the instrument evaluates distinct aspects of the family en- 


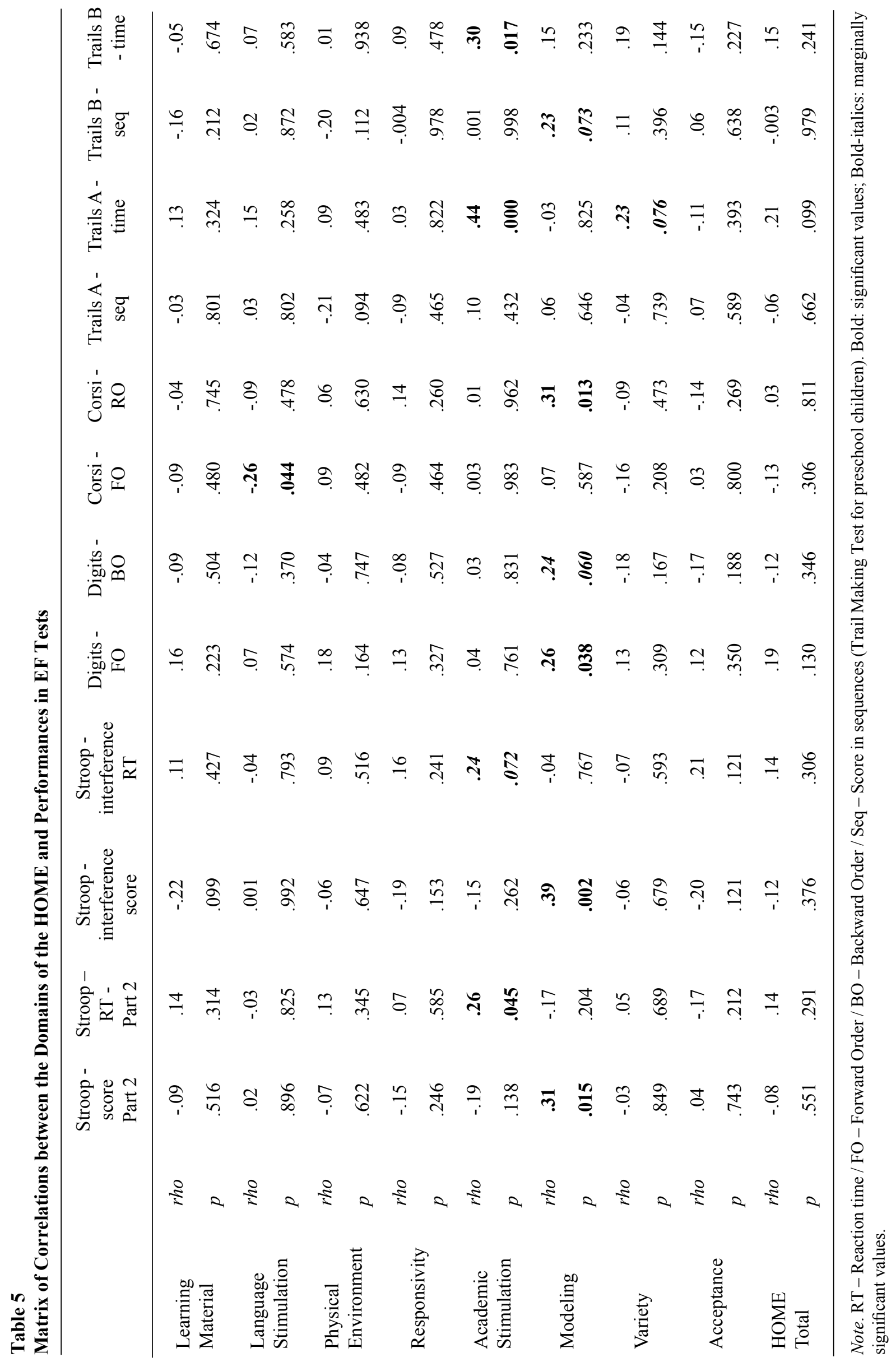


vironment. Accordingly, Goemans et al. (2014) stated that there is no evidence of unidimensionality for the HOME, as there is no single latent factor underlying the items.

The relationships of the domains with the total in the EC-HOME varied in magnitude. As also observed by Caldwell and Bradley (2003), in the present study Learning Material was the domain that presented the highest correlation with the total. That is, the highest scores in the HOME were more associated with the presence of toys that teach colors, sizes, shapes or numbers, puzzles, children's CDs and books, and other materials. This indicates that the quality of the family environment for preschool children, as evaluated by the EC-HOME, largely reflects the presence of materials that contribute to the development of learning.

High correlations were also observed for the Responsivity and Variety domains with the total. The first refers to the interaction of family members with the child, such as hugging, cuddling, talking, responding to requests of the child and praising them. The second refers to daily activities or trips made by the child, such as traveling, organization of their own toys and having meals with parents, among other aspects. These data differ from the study of Caldwell and Bradley (2003) in which, after Learning Materials, the domains that most closely correlated with the total were Language Stimulation and Physical Environment. According to Bradley et al. (1996), these differences are expected as, in different cultures, some factors can contribute in different ways to the quality of the home environment.

Evidence of validity was verified between the relationship of the EC-HOME with external variables (Urbina, 2007), including the SES and performance in EF tests, as these are previously described variables as being related to the family environment (Cruz et al., 2011; Goemans et al., 2014; Martins et al., 2004; Sarsour et al., 2011). In general, Physical Environment was the domain that established more relationships with the variables of SES, namely the score in the ABEP and parental education (significant with maternal education, marginal with paternal education). This domain evaluates the safety of the child's environment, from the construction to the location where the child plays, whether the place is dark and drab, the amount of space in the house considering the number of inhabitants, the cleaning and organization of the house and the amount of furniture. The education levels of the mother and father were also related with Variety and the total in the EC-HOME, suggesting that parents with higher education levels tend to provide greater enrichment and variety of experiences for the child, as well as a better quality of general family environment. Environments where the parents have higher levels of education were also associated with them having more ability to deal with inappropriate behavior of children, as well as a tendency for increased availability of materials and toys that encourage learning.

The majority of these correlations were significant, though of low magnitude, corroborating other studies, such as Goemans et al. (2014). For these authors, despite the correlations being of low magnitude, the relationship between SES and the family environment indicates that higher quality and quantity of stimulation and support in the home environment is related to higher SES. It should be noted that the homogeneity of our sample in terms of SES, might have contributed to the lack of variability in the results, affecting the magnitude of the relationships observed between SES and the EC-HOME.

Finally, relationships were observed between the performance of the children in the EF tests and specific domains of the EC-HOME, especially with Academic Stimulation and Modeling, in which the relationships with the EF tests were more consistent. These domains evaluate how parents encourage children in learning situations, as well as in the organization of the routine and in the expression of behavior and feelings, among other aspects. The results observed in the present study corroborate previous findings (Martins, 2014; Sarsour et al., 2011). Specifically, it should be noted that Academic Stimulation showed relationships with measures of time both in the Stroop Semantic Test and in the Trail Making Test for preschool children. This result suggests that children whose families provide 
greater stimulation for learning tend to take longer to respond, with a possible explanation being that these children consider more before issuing a response to the task (or even tend to respond less impulsively). In turn, Modeling showed significant relationships with measures of inhibition and working memory, and a marginal tendency with the measure of flexibility. The result suggests that children from well-structured families, in terms of the use of standards or rules and the use of modeling to communicate desirable or acceptable behavior, present better EF. These results corroborate previous findings in which variables, such as the organization of the environment and the style of interaction between the child and parents, can affect EF in childhood (Bernier et al., 2012; Bibok et al., 2009; Dawson \& Guare, 2010).

Other relationships and trends have been observed, such as between the Language Stimulation domain and the performance in FO in the Corsi Block-Tapping Test, as well as between the Variety domain and the time for execution in part A of the Trail Making Test for preschool children. However there is no consistency among those findings while other associations have not been observed with the same domains in HOME, therefore those relationships seem to be spurious. Other domains of the HOME did not present relationships with the measures of EF performances. Thus, the initial hypothesis that the performances in the EF tests would tend to be more related to specific domains in HOME, which measure the interactions within the family, than to those focusing the physical environment itself, was partially corroborated. Conversely, the relationship shown with the Academic Stimulation and Modeling domains corroborate the literature (Bernier et al., 2012; Bibok et al., 2009; Dawson \& Guare, 2010), however, an expected relationship between the measures of EF and the Responsivity domain, reported in the studies of Martins (2014) and Sarsour et al., (2011), was not observed. A possible explanation for this lack of correlation, as well as for the low magnitudes of correlations in the other scales, may be the homogeneity of the sample. This may have limited the variability of responses, as the participat- ing children were from the same school and the families from the same neighborhood, sharing aspects of SES.

Thereby, future researches should address the limitations of this study, including the relatively small number of participants and the lack of heterogeneity of the sample, which was recruited by convenience. It is suggested that further studies should include participants with different SES in order to verify if the relationship of the scores in the HOME with each other and with external variables change in different socioeconomic contexts. Future studies should also consider an expansion of the age range to children of 3 to 6 years of age. Given that our sample size was small, we provided only some preliminary data about HOME's psychometric features in a Brazilian sample. Face to it, we suggest that future researches improve existing evidence and perform more sophisticated analysis, looking for items (IRT) and for the theoretical structure of the scale.

\section{Final Considerations}

The study investigated some preliminary psychometric features of the EC-HOME in a Brazilian sample, filling a gap in the national literature and instrumental and also aiming to contribute to minimize the problem of different research groups using different versions of the instrument. The EC-HOME version showed high inter-rater reliability. Satisfactory internal consistency was found only for the total scale and Physical Environment domain, with poor reliability in all other domains. The pattern of relationships between the domains showed that the instrument evaluates distinct and relatively independent aspects of the family environment. Relationships with SES variables and performance of the children in the EF tests were found, proving some evidence of the validity of the HOME for relationship with other variables. In summary, the Brazilian version of the ECHOME demonstrated some good psychometric properties, which does not rule out the need for further studies and, maybe, revision of the instrument. One limitation of the instrument re- 
lated to the format or items of the Acceptance domain should be mentioned, which seems to be greatly influenced by social desirability (punishment situations of the children tended not to occur during the visit and questions on this topic tended to be answered negatively). However, the fact that HOME is an ecological measure it may be highlighted as a positive aspect of the instrument, as well as the fact that it is used in several countries (which may allow for cross-cultural comparisons). The results presented here suggest preliminary evidence of validity and reliability, which we hope will encourage future studies and revisions of the instrument.

\section{References}

Alves, I. C. B., \& Duarte, J. L. M. (2001). Escala de Maturidade Mental de Colúmbia: Padronização brasileira. São Paulo, SP: Casa do Psicólogo.

Andrade, S. A., Santos, D. N., Bastos, A. C., Pedromônico, M. R. M., Almeida-Filho, N. D., \& Barreto, M. L. (2005). Ambiente familiar e desenvolvimento cognitivo infantil: Uma abordagem epidemiológica. Revista de Saúde Pública, 39(4), 606-11. doi:10.1590/S003489102005000400014

Associação Brasileira de Empresas de Pesquisa. (2014). Critério de classificação econômica Brasil. Retrieved from http://www.abep.org/ criterio-brasil

Bayley, N. (1993). Bayley Scales of Infant Development. San Antonio, TX: The Psychological Corporation.

Bernier, A., Carlson, S. M., Deschênes, M., \& Matte-Gagné, C. (2012). Social factors in the development of early executive functioning: A closer look at the caregiving environment. Developmental Science, 15(1), 12-24. doi:10.1111/ j.1467-7687.2011.01093.x

Bibok, M. B., Carpendale, J. I. M., \& Müller, U. (2009). Parental scaffolding and the development of executive function. In C. Lewis \& J. I. M. Carpendale (Eds.), Social interaction and the development of executive function. New Directions in Child and Adolescent Development. Wiley Company.

Bradley, R. H., Corwyn, R. F., \& Whiteside-Mansell, L. (1996). Life at home: Same time, different places - an examination of the HOME inventory in different cultures. Early Development and Parenting, 5(4), 251-269. doi:10.1002/ (SICI) 1099-0917(199612)5:4<251::AIDEDP137>3.0.CO;2-I

Caldwell, B. M., \& Bradley, R. H. (1984). Home observation for measurement of the environment. Tempe, AZ: Family \& Human Dynamics Research Institute, Arizona State University.

Caldwell, B. M., \& Bradley, R. H. (2003). Home observation for measurement of the environment: Administration manual. Tempe, AZ: Family \& Human Dynamics Research Institute, Arizona State University.

Cruz, O., Abreu-Lima, I., Barros, S., Costa, P., \& Pacheco, C. (2011). A escala de avaliação do ambiente familiar comparação dos resultados observados com três versões da HOME. In VIII Congresso Iberoamericano de Avaliação/Evaluación Psicológica e XV Conferência Internacional Avaliação Psicológica: Formas e contextos, Actas (pp. 1507-1519). Lisboa: Universidade do Porto.

Dancey, C. P., \& Reidy, J. (2006). Estatística sem matemática para psicologia. Porto Alegre, RS: Artmed.

Dawson, P., \& Guare, R. (2010). Executive skills in children and adolescents: A practical guide to assessment and intervention. New York: The Guilford Press.

Diamond, A. (2013). Executive functions. Annual Review of Psychology, 64, 135-168. doi:10.1146/ annurev-psych-113011-143750

Dias, N. M., \& Seabra, A. G. (2013). Funções executivas: Desenvolvimento e intervenção. Temas sobre Desenvolvimento, 19(107), 206-212.

Glad, J., Jergeby, U., Gustafsson, C., \& Sonnander, K. (2012). Social work practitioners' experience of the clinical utility of the Home Observation for Measurement of the Environment (HOME) Inventory. Child \& Family Social Work, 17(1), 23-33. doi:10.1111/j.1365-2206.2011.00769.x

Goemans, A., van Geel, M., Vedder, P., \& Bradley, R. H. (2014). HOME in the Netherlands Validation of the Home Observation for Measurement of the Environment Inventory. Journal of Family Issues. doi:10.1177/0192513X14555767

Hammond, S. I., Müller, U., Carpendale, J. I., Bibok, M. B., \& Liebermann-Finestone, D. P. 
(2012). The effects of parental scaffolding on preschoolers' executive function. Developmental Psychology, 48(1), 271. doi:10.1037/a0025519

Lezak, M. (1995). Neuropsychological Testing. Oxford, UK: University Press.

Martins, G. L. L. (2014). O ambiente familiar e o desenvolvimento das funções executivas: Estudo correlacional com crianças de 3 a 6 anos (Master's thesis, Programa de Distúrbios do Desenvolvimento, Universidade Presbiteriana Mackenzie, São Paulo, SP, Brazil).

Martins, M. D. F. D., da Costa, J. S. D., Saforcada, E. T., \& Cunha, M. D. da C. (2004). Qualidade do ambiente e fatores associados: Um estudo em crianças de Pelotas, Rio Grande do Sul, Brasil. Cadernos de Saúde Pública, 20(3), 710-718. doi:10.1590/S0102-311X2004000300007

Marturano, E. M. (2006). O inventário de recursos do ambiente familiar. Psicologia: Reflexão e Crítica, 19(3), 498-506. doi:10.1590/S010279722006000300019

Natale, L. L., Teodoro, M. L. M., Barreto, G. D. V., \& Haase, V. G. (2008). Propriedades psicométricas de tarefas para avaliar funções executivas em pré-escolares. Psicologia em Pesquisa, 2(2), 23-35.

Noble, K. G., Houston, S. M., Kan, E., \& Sowell, E. R. (2012). Neural correlates of socioeconomic status in the developing human brain. Developmental Science, 15(4), 516-527. doi:10.1111/ j.1467-7687.2012.01147.x.

Noble, K. G., Houston, S. M., Brito, N. H., Bartsch, H., Kan, E., Kuperman, J. M., ...Sowell, E. R. (2015). Family income, parental education and brain structure in children and adolescents. $\mathrm{Na}$ ture Neuroscience, 18(5), 773-778. doi:10.1038/ nn.3983

Santos, F. H. (2005). Desenvolvimento da Memória Operacional. In C. B. Mello., M. C. Miranda., \& M. Muszkat (Eds.), Neuropsicologia do Desenvolvimento: Conceitos e abordagens (pp. 77-92). São Paulo, SP: Memnon Edições Científicas.
Sarsour, K., Sheridan, M., Jutte, D., Nuru-Jeter, A., Hinshaw, S., \& Boyce, W. T. (2011). Family socioeconomic status and child executive functions: The roles of language, home environment, and single parenthood. Journal of the International Neuropsychological Society, 17(1), 120132. doi:10.1017/S1355617710001335

Trevisan, B. T. (2010). Atenção e controle inibitório em pré-escolares e correlação com indicadores de desatenção e hiperatividade (Master's thesis, Programa de Distúrbios do Desenvolvimento, Universidade Presbiteriana Mackenzie, São Paulo, SP, Brazil).

Trevisan, B. T., Hipólito, R., Parise, L. F., Reppold, C. T., \& Seabra, A. G. (2012). Dados Normativos do Teste de Trilhas para pré-escolares. In A. G. Seabra \& N. M. Dias (Eds.), Avaliação Neuropsicológica Cognitiva: Atenção e funções executivas (pp. 90-91). São Paulo, SP: Memnon.

Trevisan, B. T., \& Prust, A. P. (2012). Evidências de validade do Teste de Trilhas para pré-escolares. In A. G Seabra \& N. M. Dias (Eds.), Avaliação Neuropsicológica Cognitiva: Atenção e funções executivas (pp. 86-89). São Paulo, SP: Memnon.

Trevisan, B. T., \& Seabra, A. G. (2012). Teste de trilhas para pré-escolares. In A. Seabra \& N. Dias (Eds.), Avaliação Neuropsicológica Cognitiva: Atenção e funções executivas (pp. 92-100). São Paulo, SP: Memnon.

Urbina, S. (2007). Fundamentos da Testagem Psicológica. Porto Alegre, RS: Artmed. 